Research Article

\title{
Evaluation of anti-inflammatory potential of ayurvedic formulation Rheumacure in animal model of rheumatoid arthritis
}

\author{
Vinit D. Patel ${ }^{1}$, Namrata A. Desai ${ }^{2}$, Praboth V. Shah ${ }^{3}$, Snehal S. Patel ${ }^{4}$ *
}

${ }^{1}$ Medip Academy, S.G.

Highway, Bodakdev,

Ahmedabad-380015, Gujarat,

India,

${ }^{2}$ Torrent Research Centre, Nr.

Kanoria Hospital, Bhat,

Ahmedabad, Gujarat 382424,

Gujarat, India,

${ }^{3}$ Department of Pharmacology,

Institute of Pharmacy, Nirma

University, Ahmedabad-382

481, Gujarat, India,

${ }^{4}$ Virgo UAP Pharma Pvt. Ltd., Sarkhej-Bavala Road, Moraiya, Sanand, Ahmedabad, 382213, Gujarat, India

Received: 03 March 2016

Accepted: 16 March 2016

*Correspondence to:

Dr. Snehal S. Patel,

Email: snehalpharma53@

gmail.com

Copyright: (C) the author(s), publisher and licensee Medip Academy. This is an openaccess article distributed under the terms of the Creative Commons Attribution NonCommercial License, which permits unrestricted noncommercial use, distribution, and reproduction in any medium, provided the original work is properly cited.

\begin{abstract}
Background: Rheumacure (RC) is a herbomineral preparation recommended by Ayurvedic medical practitioners for treatment of rheumatoid arthritis. The present study was designed to evaluate the effect of oral treatment with the herbomineral formulation in animal model of Freund's adjuvant induced arthritis to develop scientific evidence to the efficacious claim of the use of ayurvedic proprietary medicine in the management of rheumatoid arthritis in folklore medicine.

Methods: Arthritis was induced by sub plantar injection of $0.1 \mathrm{ml}$ of complete Freund's adjuvant. Treatment with RC $100 \mathrm{mg} / \mathrm{kg}$ and dexamethasone $2 \mathrm{mg} / \mathrm{kg}$ was given to rats orally once a day from day 1 to day 21 and after which estimation of physical, biochemical, and haematological parameters were carried out.

Results: Treatment of RC to arthritic animal showed statistically significant $(\mathrm{p}<0.05)$ improvement in physical parameters like arthritic index, paw edema, paw thickness, splenomegaly and thymus index of the animal. The treatment also showed significantly $(\mathrm{p}<0.05)$ reduction in inflammatory markers like $\mathrm{C}$ reactive protein, serum rheumatoid factor, erythrocyte sedimentation rate and increase in $\%$ haemoglobin. The histopathological examination showed protective effect against hyperplasia of synovium, pannus formation and destruction of the joint space.

Conclusions: The results obtained in experiments indicated significant antiinflammatory effect comparable to dexamethasone and without significant side effect. Thus the RC may be a potential preventive or therapeutic candidate for the treatment of chronic inflammation and arthritis.
\end{abstract}

Keywords: Anti-inflammatory, Ayurvedic formulation, Complete Freund's adjuvant, RCs, Rheumatoid arthritis

\section{INTRODUCTION}

Rheumatoid arthritis (RA) is a disease where joints get targeted by immune system of self. It is a systemic, inflammatory disease that attacks the synovial membranes surrounding the lubricating fluid in the joint.
The cartilage, along with the bone structure is slowly destroyed, leading to scar tissue formation. ${ }^{1,2}$ Though several drugs are available e.g. nonsteroidal antiinflammatory drugs, glucocorticoid and disease modifying anti-rheumatic drugs for managing moderate to severe cases of arthritic pain, stiffness and 
inflammation, the side effects of these drugs are often deleterious, which includes gastrointestinal irritation, cardiovascular problem, drug dependency. ${ }^{3,4}$ All these drawbacks of available medications have revived the interest in our traditional system of medicine.

According to the ayurvedic pharmacopoeia, $\mathrm{RC}$ is a herbomineral formulation believed to have the potential for providing relief to RA patients. This formulation is prepared from parts of three different plants (Colchicum luteum, Vitex negundo, Strychnos nuxvomica), Mahayogaraj Guggulu, Trayodashang Guggulu, Maharasnadi Kwath, Suvarna Makshik Bhasma and Shankh Bhasma that are used in traditional medicine for a variety of purposes. The anti-arthritic properties of this formulation have not been subject to any scientifically controlled investigations so far. Therefore the present study was designed to evaluate the effect of oral treatment with the herbomineral formulation in animal model of Freund's adjuvant induced arthritis.

\section{METHODS}

\section{Materials}

All the plants used in formulation were authenticated and formulation was prepared by Virgo UAP Pharma Pvt. Ltd. Sanand, (Ahmedabad, Gujarat, India) named as RC (RC) (Table 1) on the basis of an official ayurvedic formulary. ${ }^{5}$ Complete Freund's adjuvant (CFA) was purchased from Sigma Chemicals (St. Louis, USA). Creactive protein (CRP), serum rheumatoid factor kits were purchased from Span Diagnostics (Vadodara, India). Other chemicals used were of analytical grade.

Table 1: Composition of Rheumacure capsule.

\begin{tabular}{|llll|}
\hline Ingredients & $\begin{array}{l}\text { Botanical } \\
\text { name }\end{array}$ & $\begin{array}{l}\text { Part } \\
\text { used }\end{array}$ & $\begin{array}{l}\text { Composition } \\
\%\end{array}$ \\
\hline Suranjan & $\begin{array}{l}\text { Colchicum } \\
\text { luteum }\end{array}$ & Rhizome & $50 \mathrm{mg}$ \\
\hline Nirgundi & $\begin{array}{l}\text { Vitex } \\
\text { negundo }\end{array}$ & Leaf & $30 \mathrm{mg}$ \\
\hline $\begin{array}{l}\text { Suddha } \\
\text { Kuchala }\end{array}$ & $\begin{array}{l}\text { Srychnos } \\
\text { nuxvomica }\end{array}$ & Seed & $30 \mathrm{mg}$ \\
\hline $\begin{array}{l}\text { Mahayogaraj } \\
\text { Guggulu }\end{array}$ & $\begin{array}{l}\text { Commiphora } \\
\text { mukul }\end{array}$ & Powder & $72 \mathrm{mg}$ \\
\hline $\begin{array}{l}\text { Trayodashang } \\
\text { Guggulu }\end{array}$ & - & Powder & $50 \mathrm{mg}$ \\
\hline $\begin{array}{l}\text { Maharasnadi } \\
\text { Kwath }\end{array}$ & - & Extract & $50 \mathrm{mg}$ \\
\hline $\begin{array}{l}\text { Suvarna } \\
\text { Makshik } \\
\text { Bhasma }\end{array}$ & - & Powder & $5 \mathrm{mg}$ \\
\hline $\begin{array}{l}\text { Shankh } \\
\text { Bhasma }\end{array}$ & - & Powder & $60 \mathrm{mg}$ \\
\hline Excipients & - & - & Q.S. \\
\hline
\end{tabular}

\section{Experiment animals}

All experiments and protocols described in present study were approved by the Institutional Animal Ethics Committee (IAEC) of Institute Of Pharmacy, Nirma University, Ahmedabad (IPS/PCOL/CONS11-12/2002). Healthy wistar rats $(250-300 \mathrm{gm})$ were procured from Torrent Research Centre, Gandhinagar, Ahmedabad. Animals were housed in group of 6 animals in the animal house of Nirma University, Ahmadabad under controlled conditions of temperature $23 \pm 2^{\circ} \mathrm{C}$, relative humidity $55 \pm 5 \%$, and photo-schedule (12 h light and $12 \mathrm{~h}$ dark). Animals had free access to food and purified water ad libitum. Animals were acclimatized for one week before starting the experiment. The pharmacological work was carried out as per norms of Committee for the Purpose of Control and Supervision of Experiments on Animals (CPCSEA).

\section{Experimental protocol}

Wistar rats divided in to four groups: Normal control group, control treated with RC (100 mg/kg), control treated with dexamethasone $(2 \mathrm{mg} / \mathrm{kg})$, disease control group, disease treated with $\mathrm{RC}(100 \mathrm{mg} / \mathrm{kg})$, disease treated with dexamethasone $(2 \mathrm{mg} / \mathrm{kg})$. Arthritis was induced by sub plantar injection of $0.1 \mathrm{~mL}$ of CFA in left hind paw. ${ }^{6}$ Treatment with the test compounds is started on the day 1 and continued for 21 days. Paw volumes and paw thickness were recorded on the day of injection as well as $5^{\text {th }}$ day and $21^{\text {st }}$ day, plethysmographically. Physical parameters like body weight, arthritic index were measured after experimental period. Blood will be collected from retro orbital plexus for measurement of biochemical and haematological parameters like serum C-reactive protein (CRP), serum rheumatoid factor, haemoglobin \% and erythrocyte sedimentation rate as an indicative of inflammation. Body weight measurements were carried out weekly. On day 21, Rats were sacrificed and splenomegaly and thymus weight to body weight ratio was measured and ankle joints were subjected to histopathological studies.

\section{Statistical analysis}

Values are expressed as mean \pm standard error of the mean. The results were analysed using one-way factorial analysis of variance (ANOVA) followed by Tukey's multiple comparison test using Graphpad Prism 5 software. The value of $\mathrm{P}$ less than $5 \%(\mathrm{p}<0.05)$ was considered as statistically significant.

\section{RESULTS}

\section{Effect of formulation RC on physical parameters}

\section{Body weight gain}

There was gradual but statistically significant reduction in body weight observed in disease control groups while 
no significant difference was observed in normal control group as well as control treated with $\mathrm{RC}$ and dexamethasone. Treatment with $\mathrm{RC}$ and dexamethasone produced increase in body weight as compared to disease control group but it was not statistically significant (Figure 1A).

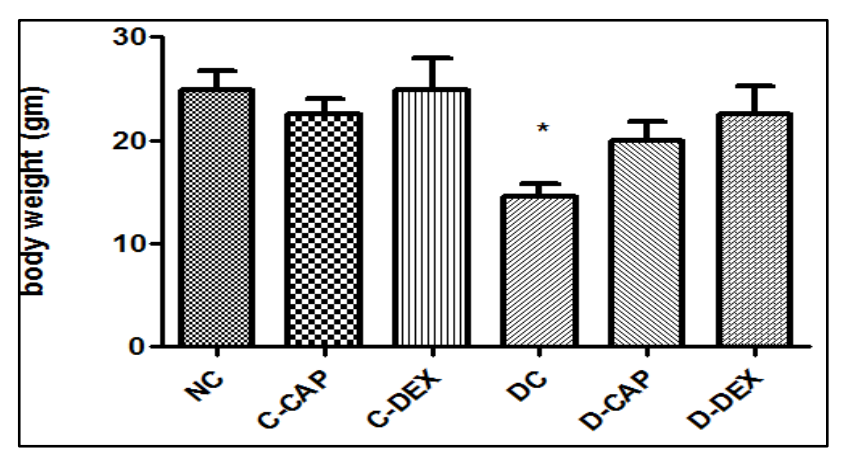

Figure 1A: Effect of formulation on physical parameters: Body weight gain.

\section{Arthritic index}

Freund's adjuvant-induced arthritic animals produced statistically significant $(p<0.05)$ increase in arthritic index in disease control group as compared to normal control group. Treatment with RC and dexamethasone to diseased animal showed statistically significant $(\mathrm{p}<0.05)$ reduction in arthritic score compared to disease control group. The formulation produced effect comparable to dexamethasone, while treatment with $\mathrm{RC}$ and dexamethasone to normal animal did not showed any significant change in paw thickness as compared to normal control group (Figure 1B).

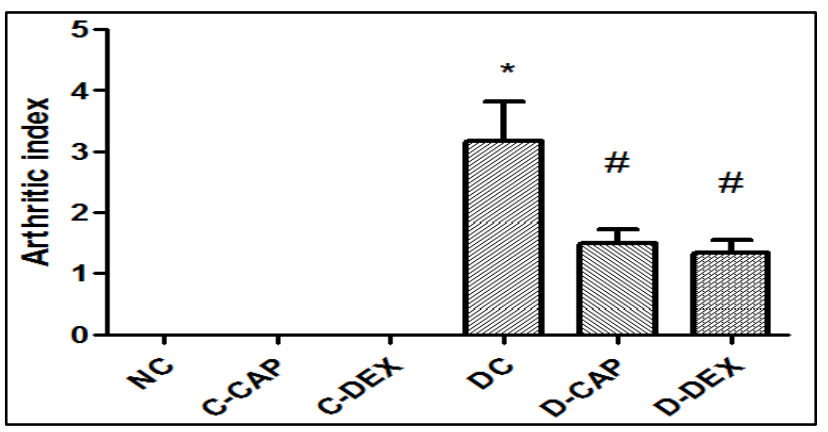

Figure 1B: Effect of formulation on physical parameters: Arthritic index.

Paw volume and paw thickness

Freund's adjuvant-induced arthritic animals produced statistically significant $(\mathrm{p}<0.05)$ increase in paw volume and paw thickness in disease control group as compared to normal control group. Treatment with RC and dexamethasone to diseased animal showed statistically significant $(\mathrm{p}<0.05)$ reduction in paw volume and paw thickness compared to disease control group. The formulation produced effect comparable to dexamethasone, while treatment with RC and dexamethasone to normal animal did not showed any significant change in paw thickness and paw volume as compared to normal control group (Figure 1C and 1D).

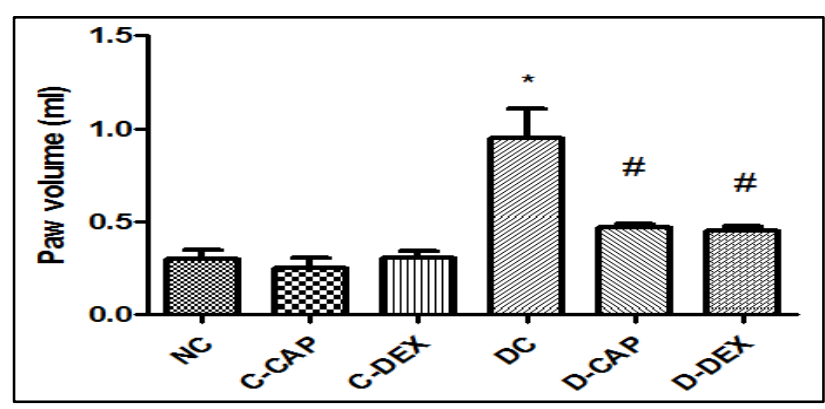

Figure 1C: Effect of formulation on physical parameters: Paw volume.

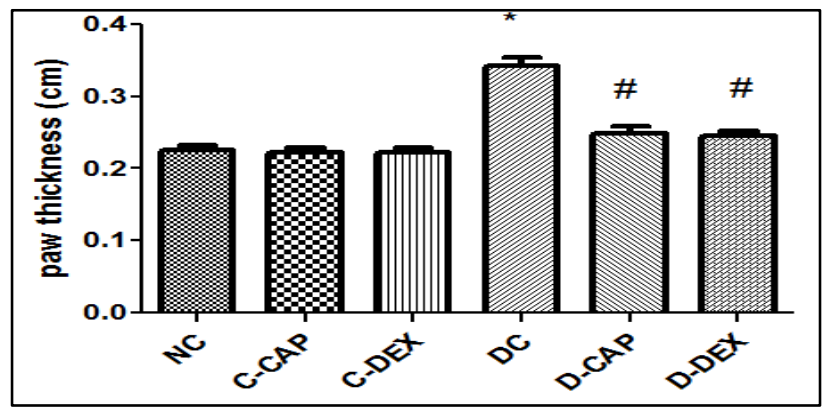

Figure 1D: Effect of formulation on physical parameters: Paw thickness.

Each bar represents Mean \pm SEM of 6 animals.*Significantly different from normal control $(\mathrm{p}<0.05)$, \#significantly different from disease control $(\mathrm{p}<0.05)$, NCnormal control, C-TAB- Rheumacure Capsule (100 $\mathrm{mg} / \mathrm{kg}$ ), C-DEX-control treated with dexamethazone $(2 \mathrm{mg} / \mathrm{kg})$, DC-disease control group, C-TAB-disease treated with Rheumacure Capsule (100 mg/kg), D-DEXdisease treated with dexamethazone $(2 \mathrm{mg} / \mathrm{kg}$ ) (Figure 1 A, B, C, D).

\section{Effect of formulations RC on Secondary organ indexes}

Freund's adjuvant-induced arthritic animals found to exhibit statistically significant $(\mathrm{p}<0.05)$ increase in spleen index and thymus index in disease control group as compared to normal control group. Treatment with RC and dexamethasone to diseased animal showed statistically significant $(\mathrm{p}<0.05)$ reduction in spleen index and thymus index as compared to disease control group, while treatment with dexamethasone to diseased animal did not showed any protective effect on spleen and thymus index. Treatment with formulation did not showed any significant change in thymus index in normal animals, but treatment of dexamethasone to normal animal showed slight decrease in thymus index but was not statistically significant (Table 2). 
Table 2: Effect of formulations Rheumacure capsule on secondary organ indexes.

\begin{tabular}{|llllll|l|}
\hline Parameters & NC & C-CAP & C-DEX & DC & D-CAP & D-DEX \\
\hline Splenomegaly (gm) & $0.096 \pm 0.007$ & $0.095 \pm 0.005$ & $0.096 \pm 0.006$ & $0.154 \pm 0.007 *$ & $0.109 \pm 0.003 \#$ & $0.109 \pm 0.003 \#$ \\
\hline Thymus weight (gm) & $0.119 \pm 0.013$ & $0.116 \pm 0.012$ & $0.108 \pm 0.013$ & $0.073 \pm 0.004^{*}$ & $0.096 \pm 0.004 \#$ & $0.105 \pm 0.004 \#$ \\
\hline
\end{tabular}

Values are expressed as Mean \pm SEM of 6 animals, * significantly different from normal control $(\mathrm{p}<0.05)$, \#significantly different from disease control $(\mathrm{p}<0.05)$, NC-normal control, C-CAP-control treated with Rheumacure Capsule (100 mg/kg), C-DEX-control treated with Dexamethasone $(2 \mathrm{mg} / \mathrm{kg})$, DC-disease control group, D-CAP-disease treated with Rheumacure Capsule $(100 \mathrm{mg} / \mathrm{kg})$, D-DEX-disease treated with Dexamethasone $(2 \mathrm{mg} / \mathrm{kg})$ (Table 2).

Effect of formulations RC on biochemical and haematological parameters

\section{CRP and Serum rheumatoid factor}

Rats treated with Freund's adjuvant had statistically significant $(p<0.05)$ elevated levels of CRP and serum rheumatoid factor in disease control group as compared to normal control group. Treatment with $\mathrm{RC}$ and dexamethasone to diseased animal showed statistically significant $(\mathrm{p}<0.05)$ reduction in levels of CRP and serum rheumatoid factor as compared to disease control group. The formulation produced effect comparable to dexamethasone, while treatment with $\mathrm{RC}$ and dexamethasone to normal animal did not showed any significant change in paw thickness as compared to normal control group (Table 3).

Table 3: Effect of Rheumacure capsule on biochemical and haematological parameters.

\begin{tabular}{|lllllll|}
\hline Parameters & NC & C-CAP & C-DEX & DC & D-CAP & D-DEX \\
\hline CRP $(\mathrm{mg} / \mathrm{dl})$ & $4.9 \pm 0.28$ & $4.9 \pm 0.15$ & $4.92 \pm 0.21$ & $8.65 \pm 0.33 *$ & $5.85 \pm 0.49 \#$ & $5.67 \pm 0.21 \#$ \\
\hline Serum RF $(\mathrm{IU} / \mathrm{ml})$ & $50.41 \pm 2.29$ & $52.58 \pm 1.85$ & $51.42 \pm 1.64$ & $74.57 \pm 1.42 *$ & $59.05 \pm 0.72 \#$ & $56.19 \pm 1.01 \#$ \\
\hline ESR $(\mathrm{mm} / \mathrm{h})$ & $3.54 \pm 0.19$ & $3.56 \pm 0.21$ & $3.82 \pm 0.2$ & $6.32 \pm 0.15 *$ & $4.25 \pm 0.25 \#$ & $4.03 \pm 0.17 \#$ \\
\hline HB $(\mathrm{mg} \%)$ & $11.83 \pm 0.95$ & $12.15 \pm 0.52$ & $12.63 \pm 1.03$ & $19.76 \pm 0.4 *$ & $14.57 \pm 0.64 \#$ & $14.33 \pm 0.92 \#$ \\
\hline
\end{tabular}

\section{Erythrocyte sedimentation rate}

Rats treated with Freund's adjuvant had statistically significant $(\mathrm{p}<0.05)$ elevated levels of erythrocyte sedimentation rate in disease control group as compared to normal control group. Treatment with $\mathrm{RC}$ and dexamethasone to diseased animal showed statistically significant $(\mathrm{p}<0.05)$ reduction in levels of erythrocyte sedimentation rate as compared to disease control group. The formulation produced effect comparable to dexamethasone, while treatment with $\mathrm{RC}$ and dexamethasone to normal animal did not showed any significant change in paw thickness as compared to normal control group (Table 3).

\section{$\%$ Haemoglobin}

Rats treated with Freund's adjuvant had statistically significant $(p<0.05)$ decreased levels of \% haemoglobin in disease control group as compared to normal control group. Treatment with $\mathrm{RC}$ and dexamethasone to diseased animal showed statistically significant $(\mathrm{p}<0.05)$ increase in levels of percent haemoglobin as compared to disease control group. The formulation produced effect comparable to dexamethasone, while treatment with $\mathrm{RC}$ and dexamethasone to normal animal did not showed any significant change in paw thickness as compared to normal control group (Table 3).

Values are expressed as Mean \pm SEM of 6 animals, *Significantly different from normal control $(p<0.05)$, \#significantly different from disease control $(\mathrm{p}<0.05)$, NC-normal control, C-CAP-control treated with Rheumacure Capsule (100 mg/kg), C-DEX-control treated with Dexamethasone $(2 \mathrm{mg} / \mathrm{kg})$, DC-disease control group, D-CAP-disease treated with Rheumacure Capsule $(100 \mathrm{mg} / \mathrm{kg})$, D-DEX-disease treated with Dexamethasone $(2 \mathrm{mg} / \mathrm{kg})$ (Table 3$)$.

\section{Effect of formulations RC on histopathology of joints}

In histopathology of ankle joints in normal control group showed normal joint structure, no cartilage distruction and no signs of inflammation or other distoration was observed. While in arthritic animals showed mild to moderate hyperplasia of synovium; focal cartilage distruction; presence of pannus formation with distruction of joint space. Treatment with RC and dexamethasone 
group showed significant improvement in hyperplasia of synovium as compared to disease control group (Figure 2).

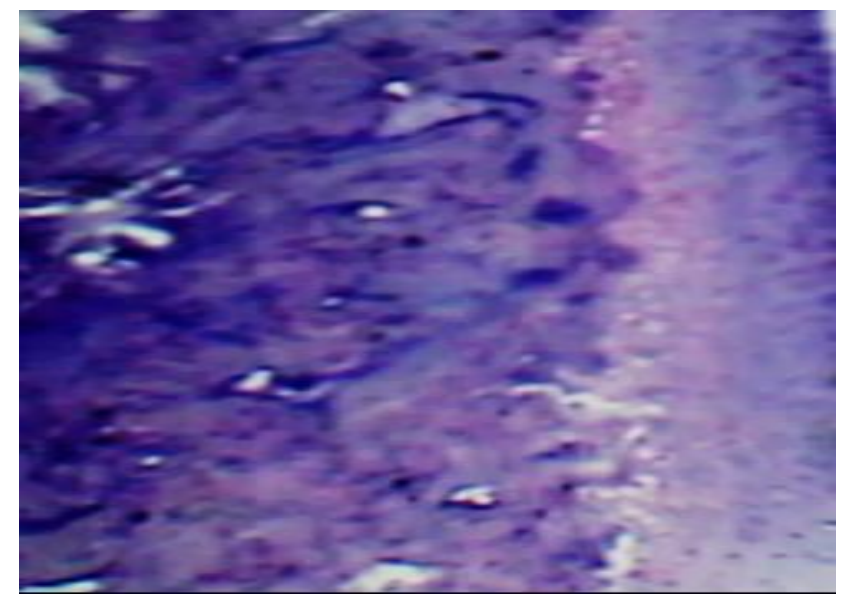

Figure 3A: Effect of formulation Rheumacure capsule on histopathology of joints: Normal control group.

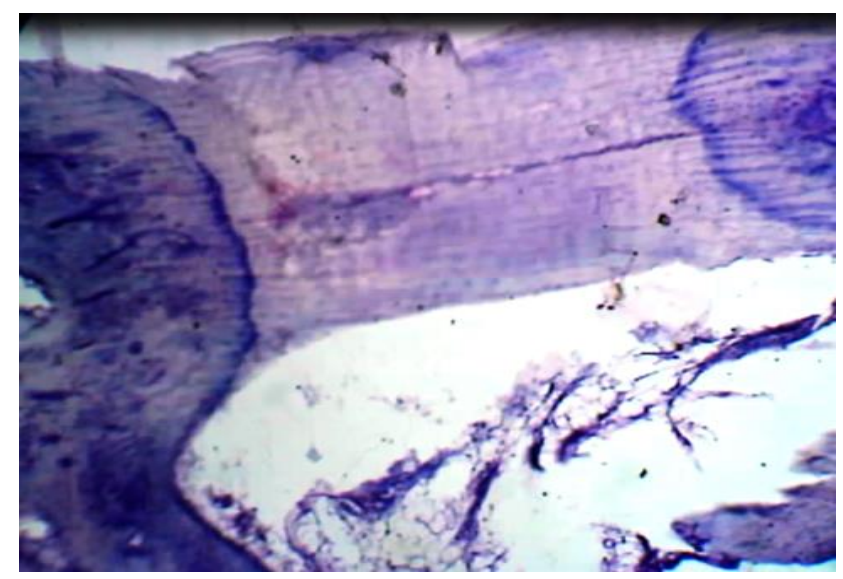

Figure 3B: Effect of formulation Rheumacure capsule on histopathology of joints: Disease control group.

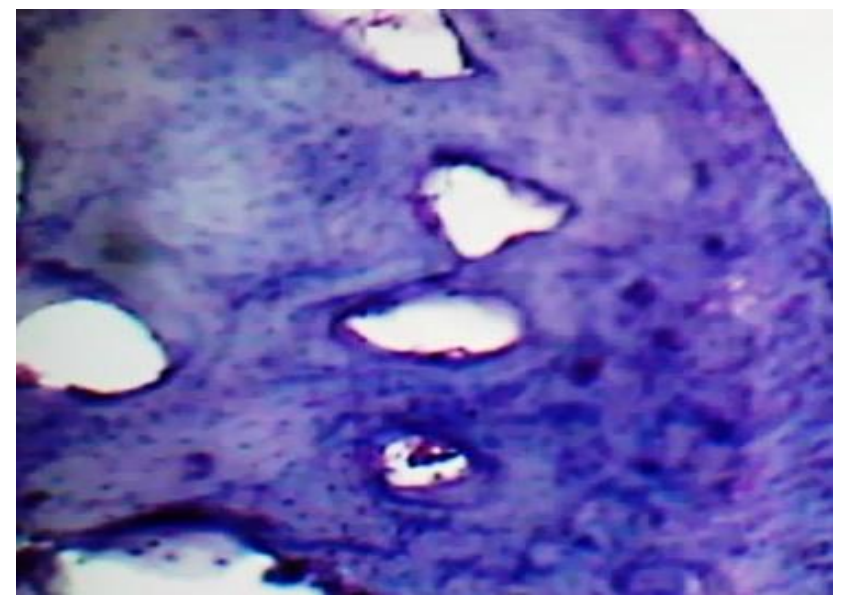

Figure 3C: Effect of formulation Rheumacure capsule on histopathology of joints: Control treated with Rheumacure capsule.

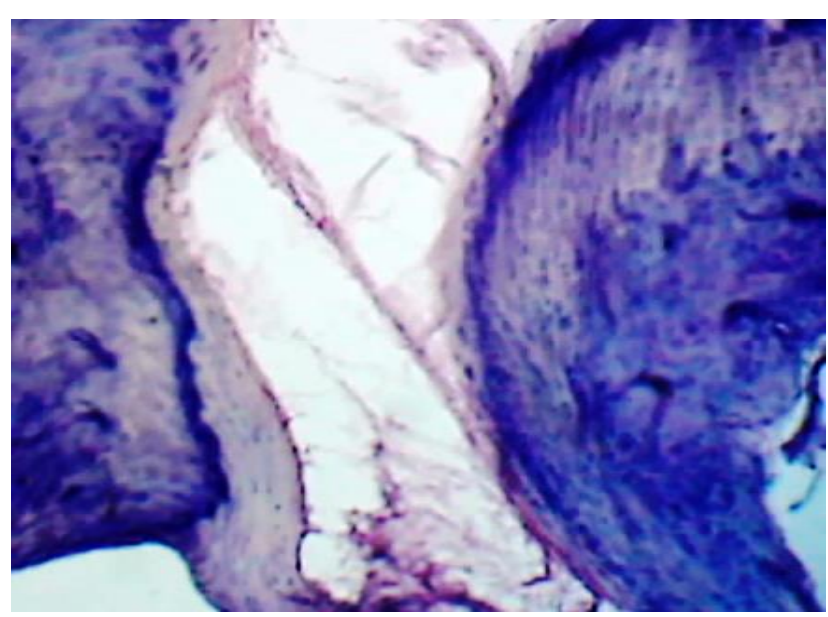

Figure 3D: Effect of formulation Rheumacure capsule on histopathology of joints: Disease treated with tablet.

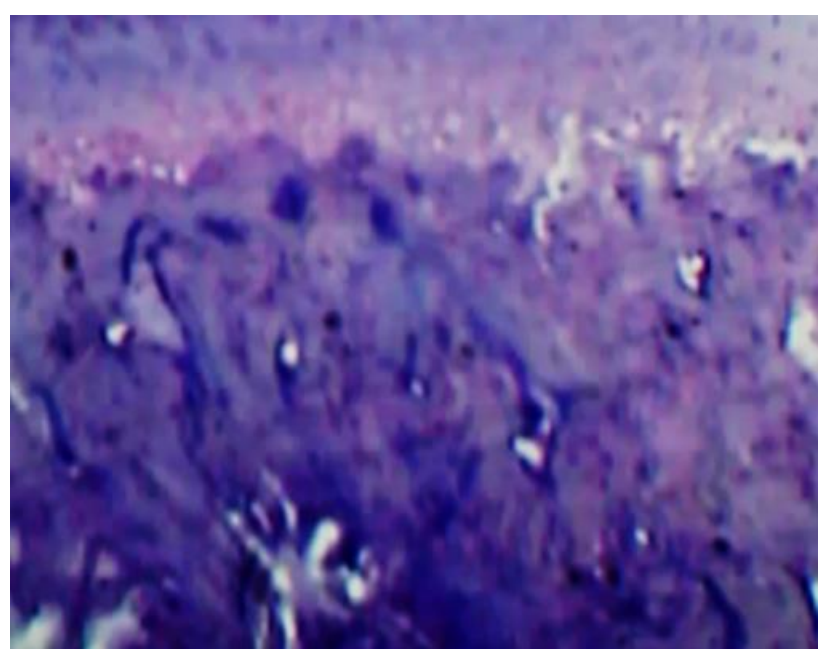

Figure 3E: Effect of formulation Rheumacure capsule on histopathology of joints: Control treated with dexamethazone.

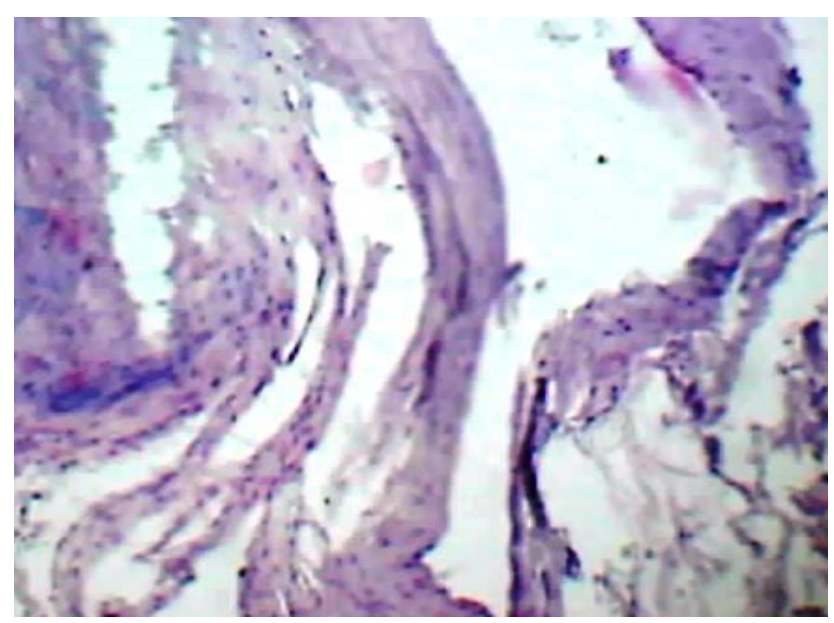

Figure 3F: Effect of formulation Rheumacure capsule on histopathology of joints: Disease treated with dexamethazone. 


\section{DISCUSSION}

CFA is animal model of RA, has been extensively used to preclinical screening of anti-arthritis compounds. After a single injection of Freund's adjuvant, polyarthritis develops with cartilage degradation, bone resorption and cellular infiltration which are observed clinically in human being. ${ }^{7,8}$

A decrease in body weight of the rats occurred during experimental period which may be due to alterations in the metabolic activities of diseased rats. The decrease in body weight gain in the arthritic rats compared to the normal control rats in the current study is in concordance with the fact that rheumatoid arthritis is associated with enhanced protein breakdown and muscle wasting in experimental arthritis. ${ }^{9,10}$ Treatment with RC to arthritic rats improved loss of body weight. These effects may be due to either inhibition of loss body's protein or inhibition of muscle wasting or improvement in inflammation.

Arthritic index is the average of the score given to severity of the lesions in the form of Inflammation and/or nodules observed on ears, nose, tail, forepaws and hind paws. A selective reduction in the arthritis score indicates anti-inflammatory effects. ${ }^{11}$ Administration of Freund's adjuvant increased arthritic index in disease control group which was significantly different from normal control group. Colchicum luteum which has been reported to have anti-arthritic activity due to its modulatory effect on the expression of pro-inflammatory cytokine in the synovium, Vitex negundo and Strychnos nuxvomica also have been reported to have anti-inflammatory and antiarthritic activity. ${ }^{12-14}$ According to Ayurveda, Maharasnadi Kwath present in formulation also reported to be used to treat muscular and joint pains. Therefore, protective effect of RC may be attributed to presence of different plants having anti-inflammatory activity and maharasnadi kwath.

The progression of arthritis is characterized by increase of the paw volumes and paw thickness, which is the characteristic of early as well as chronic phase of the disease and can be attributed to inflammation. ${ }^{11,15} \mathrm{RC}$ treated group showed significant reduction in paw volume suggesting the anti-inflammatory activity of the $\mathrm{RC}$ due to presence of anti-inflammatory constituents in different plants like guggulsterone, a steroid isolated from Commiphora mukul and tested in rats for inhibition of inflammation induced by Freund's adjuvant. ${ }^{16}$

Increase in spleen weight to body weight ratio occurs as a result of release of cytokines resulting in disruption of spleen histology. Whereas, the decrease in thymus weight is due to a suppression of immune system. ${ }^{17,18}$ Treatment produced decrease in index of spleen of the arthritic rats, whereas no significant impact on the index of thymus was observed. The decrease in thymus weights in the dexamethasone treated rats was higher as compared to
$\mathrm{RC}$ treated group indicates that RC played an important role in the immune system mainly by inhibiting the enlargement of the spleen and the expansion of immune cells of thymus, which may be due to presence of suvarna makshik bhasma and shankh bhasma, a mineral which has been reported to have immunoprotective effects. ${ }^{19}$

CRP levels are closely linked to inflammation progression in response to action of interlukin- $6 .^{21}$ The treatment with RC significantly reduced the levels of CRP. The effect may be due to suppression of inflammation and inhibition of synthesis of chemical mediators because RC contains Mahayogaraj Guggulu, Trayodashang Guggulu which have been proved to be anti-inflammatory by the mechanisms may be associated with the inhibition of inflammatory mediator overproduction. ${ }^{17}$ The RC also contains Maharasnadi Kwath, Suvarna Makshik Bhasma and Shankh Bhasma which is a very famous Ayurvedic medicine used in Vata disorders like Kampavata, hemiplegia, paraplegia, Neck pain, low back pain, rheumatoid arthritis, osteoarthritis, knee pain and hip pain.

Rheumatoid factor is biomarker for rheumatoid arthritis. ${ }^{22}$ Diseased control group showed significantly elevated levels of serum rheumatoid factor compared to normal control group. The treatment with RC significantly reduced the levels of these biomarkers and indicates that the anti-inflammatory effects of RC. RA accompanied by raised ESR, which is the indicator of chronic inflammatory disease state. ${ }^{23}$ Treatment with RC showed reduction in ESR support its anti-arthritic effect. The reduction in the $\mathrm{Hb}$ count during arthritis results from reduced erythropoietin levels induced by inflammation. ${ }^{24}$ Increase in the $\mathrm{Hb}$ count brought about by $\mathrm{RC}$ further supports its protective effect against anaemia of inflammation.

Histopathological evaluations of ankle joints of disease control rats showed marked damage and presence of pannus formation. The pannus formation is associated with inhibition of neutrophil infiltration. ${ }^{25,26}$ Treatment with RC showed protective effect support its anti-arthritic effect. The inhibition of pannus formation and bone erosion may be associated with inhibition of neutrophil infiltration.

\section{CONCLUSION}

From this study, it could be concluded that RC, a combination of herbal plants with Mahayogaraj Guggulu, Trayodashang Guggulu, Maharasnadi Kwath, Suvarna Makshik Bhasma and Shankh Bhasma exert a significant anti-inflammatory and immunosuppressive effect. This could be due to different types of active principles and different mechanism of action. However, the overall side effects like splenomegaly and thymus suppression observed with RC are less than that with dexamethasone which could be due to different mechanism of action of individual constituent present in RC. Therefore 
combination of plants with minerals is beneficial because combination of two or more compounds with different mechanism of action may have synergetic effect or may be reducing side effect of the other constituent. Thus it is suggested that the RC may be able to be considered as safe supplementary therapy for a long term and effective management of arthritic patients.

\section{ACKNOWLDEMENTS}

This study was supported by Virgo UAP Pharma Pvt. Ltd., Ahmedabad, Gujarat, India. The authors are grateful to Virgo UAP Pharma Pvt. Ltd., for providing funds required to carry out the research work.

\section{Funding: No funding sources}

Conflict of interest: None declared

Ethical approval: The study was approved by the Institutional Ethics Committee

\section{REFERENCES}

1. Babu NP, Pandikumar P, Ignacimuthu S. Antiinflammatory activity of Albizia lebbeck Benth., an ethnomedicinal plant, in acute and chronic animal models of inflammation. Journal of Ethnopharmacology. 2009;125:356-60.

2. Arend WP, Dayer JM. Cytokine, antagonist and rheumatoid arthritis. Arthritis Rheumatoid. 1990;33:305-15.

3. Scheiman JM. The impact of nonsteroidal antiinflammatory drug-induced gastropathy. The American Journal of Managed Care. 2001;7:S10-4.

4. Jadhav RB, Patil CR, Surana SJ, Bhatnagar SP, Patil, MJ. Rheumatoid arthritis and herbal drugs: current status and future prospects. In: Govil, J.N., Singh, V.K. (Eds.), Phytopharmacology and Therapeutic Values II, vol. 20. Studium Press LLC, Houston, TX, U.S.A., 2007; pp. 277-300.

5. The Ayurveda Pharmacopoeia, 2006, Part-II. Government of India, Ministry of health and family welfare.

6. Patel SS, Shah PV. Evaluation of anti-inflammatory potential of the multidrug herbomineral formulation in male Wistar rats against rheumatoid arthritis. Journal of Ayurveda and Integrative Medicine. 2013;4(2):86-93.

7. Bendele A, McComb J, Gould T, McAbee T, Sennello G, Chlipala E, et al. Animal models of arthritis: relevance to human disease. Toxicol Pathol. 1999;27(1):134-42.

8. Zheng YQ, Wei W. Total glucosides of paeony suppresses adjuvant arthritis in rats and intervenes cytokine-signaling between different types of synoviocytes. International Immunopharmacology. 2005;5:1560-73.

9. Granado M, Priego T, Martín AI, Villanúa MA, Lopez-Calderon A. Ghrelin receptor agonist GHRP-2 prevents arthritis-induced increase in E3 ubiquitinligating enzymes MuRF1 and MAFbx gene expression in skeletal muscle. Am J Physiol Endocrinol Metab. 2005;289(6):E1007-14.

10. Lecker $\mathrm{SH}$. Ubiquitin-protein ligases in muscle wasting: multiple parallel pathways? Curr Opin Clin Nutr Metab Care. 2003;6(3):271-5.

11. Yu Y, Xiong Z, Lv Y, Qian Y, Jiang S, Tian Y. In vivo evaluation of early disease progression by $X$-ray phase-contrast imaging in the adjuvant-induced arthritic rat. Skeletal Radiol. 2006;35(3):156-64.

12. Nair V, Singh S, Gupta YK. Evaluation of the disease modifying activity of Colchicum luteum Baker in experimental arthritis. J Ethnopharmacol. 2011;133(2):303-7.

13. Zheng CJ, Zhao XX, Ai HW, Lin B, Han T, Jiang YP, et al. Therapeutic effects of standardized Vitex negundo seeds extract on complete Freund's adjuvant induced arthritis in rats. Phytomedicine. 2014;21(6):838-46.

14. Yin W, Wang TS, Yin FZ, Cai BC. Analgesic and anti-inflammatory properties of brucine and brucine N-oxide extracted from seeds of Strychnos nuxvomica. J Ethnopharmacol. 2003;88(2-3):205-14.

15. Weiner HL. Induction and mechanism of action of transforming growth factor-beta-secreting Th3 regulatory cells. Immunol Rev. 2001;182:207-14.

16. Arora RB, Taneja V, Sharma RC, Gupta SK. Antiinflammatory studies on a crystalline steroid isolated from Commiphora mukul. Indian Journal of Medical Research. 1972;60:929-31.

17. Gebhard C, Stämpfli SF, Gebhard CE, Akhmedov A, Breitenstein A, Camici GG, et al. Guggulsterone, an anti-inflammatory phytosterol, inhibits tissue factor and arterial thrombosis. Basic Res Cardiol. 2009;104(3):285-94.

18. Marchetti B, Morale MC, Testa N, Tirolo C, Caniglia S, Amor S, Dijkstra CD, Barden N. Stress, the immune system and vulnerability to degenerative disorders of the central nervous system in transgenic mice expressing glucocorticoid receptor antisense RNA. Brain Res Brain Res Rev. 2001;37(1-3):25972.

19. Bello AE, Oesser S. Collagen hydrolysate for the treatment of osteoarthritis and other joint disorders: A review of the literature. Curr Med Res Opin. 2006;22:2221-32.

20. Galib R, Kar AC, Narayana A. Standardization of bhasmas - Need of the hour. J Ayurveda. 2008;2:2733.

21. Nielen MMJ, van Schaardenburg D, Reesink HW, Twisk JWR, van de Stadt RJ, van der HorstBruinsma IE, et al. Simultaneous development of acute phase response and autoantibodies in preclinical rheumatoid arthritis. Ann Rheum Dis. 2006;65(4):535-7.

22. Dörner T, Egerer K, Feist E, Burmester GR. Rheumatoid factor revisited. Curr Opin Rheumatol. 2004;16(3):246-53.

23. Hopstaken RM, Muris JW, Knottnerus JA, Kester $\mathrm{AD}$, Rinkens PE, Dinant GJ. Contributions of symptoms, signs, erythrocyte sedimentation rate, and 
C-reactive protein to a diagnosis of pneumonia in acute lower respiratory tract infection. $\mathrm{Br} \mathrm{J}$ Gen Pract. 2003;53(490):358-64.

24. Kaltwasser JP, Kessler U, Gottschalk R, Stucki G, Moller B. Effect of recombinant human erythropoietin and intravenous iron on anemia and disease activity in rheumatoid arthritis. J Rheumatol. 2001;28:2430-6.

25. Bhat AS, Tandan SK, Kumar D, Krishna V, Prakash VR. Interaction between inhibitors of inducible nitric oxide synthase and cyclooxygenase in adjuvant- induced arthritis in female albino rats: An isobolographic study. European Journal of Pharmacology. 2007;556(1-3):190-9.

26. Nikitopoulou I, Oikonomou N, Karouzakis E, Sevastou I, Nikolaidou-Katsaridou N, Zhao Z, et al. Autotaxin expression from synovial fibroblasts is essential for the pathogenesis of modeled arthritis. Journal of Experimental Medicine. 2012;209(5):92533.

Cite this article as: Patel VD, Desai NA, Shah PV, Patel SS. Evaluation of anti-inflammatory potential of ayurvedic formulation Rheumacure in animal model of rheumatoid arthritis. Int J Basic Clin Pharmacol 2016;5:350-7. 